\title{
Análisis Morfométrico Ultraestructural de Células Normales de Glándula Parótida de Rata
}

\author{
Ultrastructural Morphometric Analysis from Normal Parotid Gland Cells of Rat
}

\author{
R. Cornejo"; O. Garrido**; F. Matamala*; H. Silva*; A. Mardones*; K. Lagos" \& O. Hueichapan*
}

CORneJO, R.; GARRIDO, O.; MATAMAla, F.; SilVA, H.; MARDONES, A.; LAGOS, K. \& HUEICHAPAN, O. Análisis

morfométrico ultraestructural de células normales de glándula parótida de rata. Int. J. Morphol., 31(4):1205-1209, 2013.

RESUMEN: A partir de 10 ratas hembras con un peso aproximado de $250 \mathrm{~g}$ y 4 meses de vida, fueron obtenidas quirúrgicamente muestras de glándula parótida las que se trataron con técnicas de microscopía electrónica de transmisión para posteriormente obtener microfotografías de células parotideas con aumentos finales de hasta $21300 \mathrm{X}$. En las citadas microfotografías se aplicaron técnicas morfométricas con el objetivo de cuantificar las fracciones volumétricas que los distintos componentes ocupan en estas células normales, describiendo de esta manera sus volúmenes y relacionándolos con la funcionalidad que desempeñan en esta célula normal. Se evaluaron las fracciones volumétricas pertenecientes a: citoplasma, núcleo, mitocondrias, retículo endoplasmático rugoso (RER), gránulos de zimógeno, eu y heterocromatina. De igual forma, se cuantificó las áreas celulares y nucleares. Contando con los datos numéricos producto de la evaluación morfométrica de sus componentes se podrá determinar el patrón de distribución de sus organelos y de funcionalidad de esta célula activa en la síntesis y secreción de proteínas representada por los gránulos de zimógeno de diastasa y diversas proteínas salivales

PALABRAS CLAVE: Morfometría; Glándula parótida; Célula acinar.

\section{INTRODUCCIÓN}

La glándula parótida es uno de los tres pares de glándulas salivales mayores presentes en la mayoría de los seres vivos, debiendo su nombre al lugar anatómico que ocupa: Para $=$ alrededor y Otid $=$ oreja (Rovira et al., 2009), y corresponden a las glándulas salivales más voluminosas alcanzando un peso de hasta $30 \mathrm{~g}$, ubicándose una a cada lado de la cara, en la celda parotídea por detrás del meato acústico externo donde su conducto excretor principal, conocido como conducto parotídeo, drena a la papila de la mucosa de la cavidad oral, a la altura del primer o segundo molar superior (Gómez De Ferraris \& Campos, 2009).

La glándula parótida está compuestas por acinos los cuales poseen exclusivamente células secretoras serosas (Ross \& Pawlina, 2007), que sintetizan y secretan el 25\% de la saliva total (Avery \& Chiego, 2007) y presenta conductos excretores largos y ramificados denominados intercalares y estriados (Kühnel, 2005) y existe frecuentemente tejido adiposo dentro de la glándula (Ross \& Pawlina).

Las células secretoras del acino seroso presentan una estructura piramidal con un núcleo central o basal (Ceccotti et al., 2007) mientras que la región apical o supra nuclear del citoplasma, se encuentra tapizada de gránulos secretorios zimogénicos que contienen amilasa salival y otras proteínas salivales (Gal Iglesias et al., 2007), donde la cantidad de estos varía de acuerdo a la actividad secretora de la célula y de su ciclo celular (Kühnel). En su citoplasma destacan el retículo endoplasmático rugoso (RER) y el complejo de Golgi, muy desarrollados para satisfacer tanto la síntesis como la secreción proteica (Avery \& Chiego).

A pesar de una exhaustiva revisión de la bibliografía consultada, no fue posible ubicar publicaciones relacionadas al volumen que los distintos componentes subcelulares ocupan en estas células normales, caracterizadas por un alto metabolismo, específicamente, en la síntesis y secreción de proteínas.

Por lo anteriormente planteado, el objetivo fundamental de la presente investigación consistió en determinar mediante técnicas morfométricas asociadas a microscopía electrónica de transmisión, las fracciones volumétricas que cada componente ocupa en estas células de parótida normal caracterizadas por un alto metabolismo en la síntesis y secreción de zimógeno.

\footnotetext{
* Depto. Ciencias Básicas, Facultad de Medicina, Universidad de La Frontera, Temuco, Chile.

*** Instituto de Ciencias Marinas y Limnológicas, Universidad Austral, Valdivia, Chile.
} 


\section{MATERIAL Y MÉTODO}

Fueron utilizadas 10 ratas hembras, de 4 meses de vida con un peso de aproximadamente $250 \mathrm{~g}$. A los animales se le extrajeron muestras de glándula parótida, las cuales fueron procesadas con técnicas de microscopía electrónica de transmisión. A las muestras se le adicionó una solución de glutaraldehído $2 \%$ en tampón fosfato $0,15 \mathrm{M}, \mathrm{pH} 7,2$ y se mantuvo a temperatura ambiente por 2 horas. Luego, fueron sometidas a un lavado en solución de $6 \mathrm{~g}$ de $\mathrm{NaCl}$ y $73 \mathrm{~g}$ de sacarosa, disuelto en 1 litro de agua destilada.

La post-fijación se realizó con tetróxido de osmio $1 \%$ disuelto en la solución, durante una hora a $40^{\circ} \mathrm{C}$ y acetato de uranilo $0,5 \%$ por 18 horas. Luego de lavado el material fue deshidratado en concentraciones crecientes de acetona (30 a 100\%) e incluido en Araldita 6005. Se obtuvieron cortes ultrafinos de aproximadamente $70 \mathrm{~nm}$ de grosor los que fueron tratados con acetato de uranilo $2 \%$ durante 40 minutos y citrato de plomo $0,5 \%$ por 10 minutos.

Las muestras fueron finalmente estudiadas y microfotografiadas sus células parotídeas en un microscopio electrónico Phillips EM 300, con aumentos de hasta $21.300 \mathrm{X}$

Para la evaluación de las fracciones volumétricas de los componentes celulares, fue sobrepuesto un retículo de puntos sobre las microfotografías electrónicas y se procedió al conteo diferencial de los puntos que incidían sobre los perfiles de los componentes, calculándose la fracción volumétrica que ellos ocupan mediante la siguiente ecuación (Weibel, 1969): $\mathrm{Fv}=\mathrm{Pi} / \mathrm{Pt}$, donde $\mathrm{Fv}=$ Fracción volumétrica del componente celular, $\mathrm{Pi}=\mathrm{Pun}-$ tos incidentes sobre el componente en estudio y $\mathrm{Pt}=$ Puntos totales incidentes en la célula estudiada.

Análisis estadístico. Todos los datos cuantitativos obtenidos fueron sometidos a la prueba de Wilcoxon mediante el paquete estadístico SPSS versión 15 para Windows (Chicago, USA) para muestras no paramétricas estableciendo diferencias con un valor de $Z=2,023$ y un $p=0,043$ indicando entonces que existen diferencias significativas entre ellos.

\section{RESULTADOS}

Las fracciones volumétricas expresadas en porcentajes evaluadas mediante técnicas morfométricas en células de parótida normal de rata, dependiendo de la actividad sintetizadora de su ciclo celular, se tradujeron citológicamente en los siguientes resultados:

El 9\% del volumen celular correspondió a los gránulos de secreción proteica, en forma de zimógenos, que se disponen periféricamente en la región apical del citosol y básicamente supranuclear, heterogéneos respecto a sus dimensiones, y caracterizados por una alta densidad electrónica (Fig. 1).

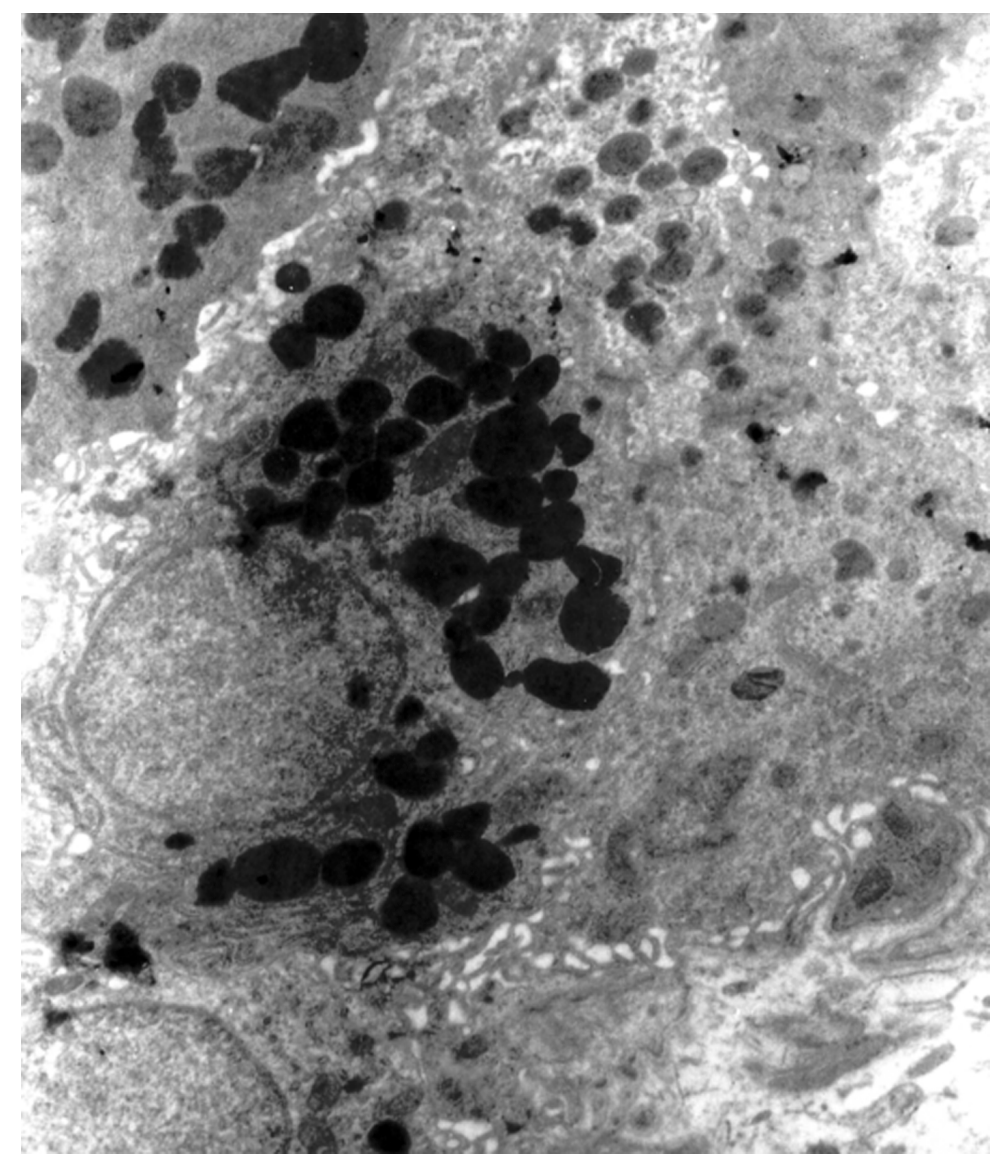

Fig. 1. Microfotografía electrónica de transmisión correspondiente a células de parótida de rata normal. 21.300X.

Con respecto a las fracciones volumétricas del retículo endoplasmático rugoso (RER) fue determinado morfométricamente que este ocupa un $7 \%$ del volumen celular, dato cuantitativo que se condice con la cantidad de gránulos proteicos y zimogénicos, sintetizados y temporalmente almacenados citoplasmáticamente, en este tipo celular (Fig. 2). 


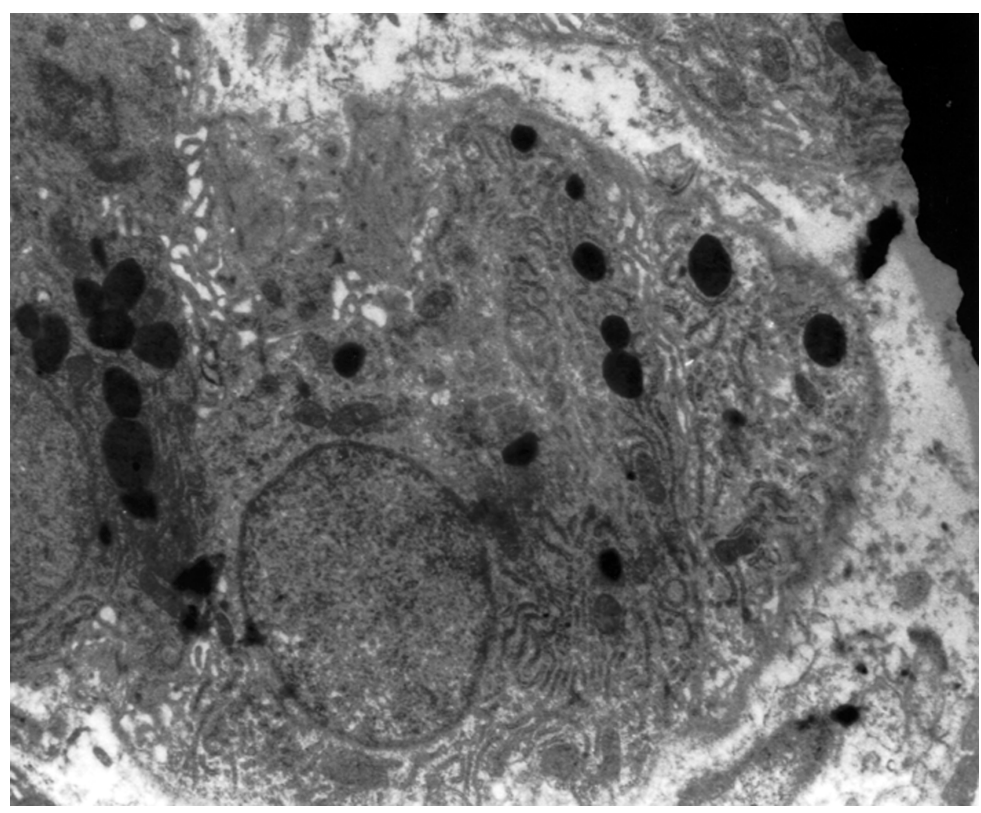

Fig. 2. Microfotografía electrónica de transmisión correspondiente a células de parótida de rata normal. 18.000X.

En lo relativo al volumen mitocondrial evaluado en este tipo celular de alto metabolismo alcanza a un $6 \%$ del volumen celular, esta fracción volumétrica, permite satisfacer las necesidades energéticas, para la síntesis, traslado y secreción de los zimógenos descritos.

El núcleo de esta célula acinar corresponde a una estructura esferoidea, ubicado basalmente y que ocupa un $22 \%$ del volumen celular. Fue cuantificado en su estructuración un $80 \%$ correspondiente a eucromatina y un $20 \%$ de heterocromatina, estos porcentajes indican claramente que a partir del compartimiento nuclear se genera una alta tasa de expresión génica, cuya traducción supone una activa síntesis proteica.

Finalmente, en lo relacionado con el volumen citosólico un 78\% indica un espacio apropiado para, por un lado albergar los organelos destinados para la síntesis, como así mismo almacenar y exportar los zimógenos sintetizados (Fig. 3).

Las áreas celulares y nucleares expresadas en micrones cuadrados, pertenecientes a células de parótida normal de rata correspondieron a $242 \mu^{2}$ y $49 \mu^{2}$, respectivamente.

\section{DISCUSIÓN}

Como fue señalado anetriormente, no fue encontrado en la literatura consultada referencias respecto a la evaluación cuantitativa precisa y completa, relativa a los volúmenes correspondientes que los componentes celulares ocupan en estas células acinares de la parótida, ca-

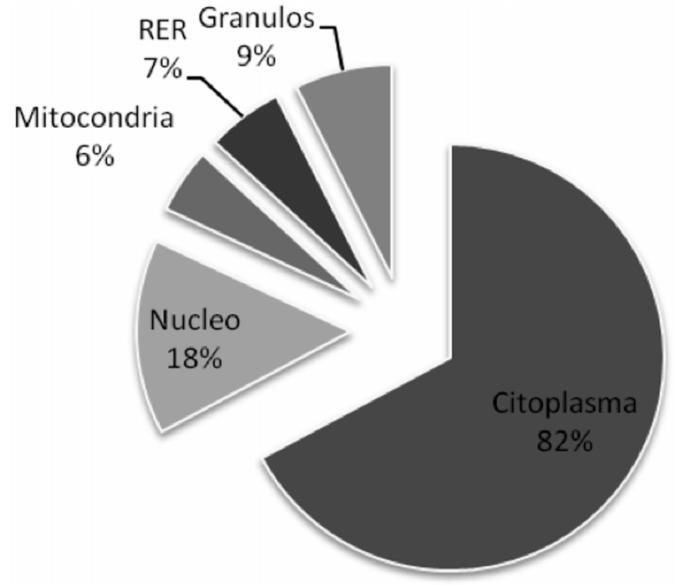

Fig. 3. Fracciones volumétricas expresadas en porcentaje correspondientes a componentes pertenecientes a células acinares de parótida normal de rata.

racterizada por su elevada capacidad sintetizadora y secretoria de proteínas.

En este sentido, quizás la única referencia a un estudio morfométrico de componentes pertenecientes a células acinares de la glándula parótida, ha sido realizado en conejo por Cope (1978), el cual informó de un volumen mitocondrial correspondiente a $16,5 \%$ del volumen celular, resultado que difiere del nuestro que alcanza solo a un 5,5\%. De igual manera aquel estudio de Cope indica que evaluado el área celular, este alcanza a 375 micrones cuadrados, muy superior a los 242 cuantificados en nuestro estudio.

En relación a los gránulos proteicos de los zimógenos que hemos descrito evidenciados tanto en la Figuras 1 y 2, caracterizados tanto por su heterogeneidad como por su electrodensidad, coincide plenamente con lo publicado por Amsterdam et al. (1969) los cuales observan estas características en células acinares de la glándula parótida de rata, precisando además su ubicación en el citoplasma apical y el rol de sus membranas durante la fisiología correspondiente a la depletación de su contenido zimogénico.

De igual manera, Riva et al. (1976) determinaron similares características, además hicie- 
ron referencia al tamaño de los gránulos precisándolos entre 1 a $15 \mathrm{~mm}$ de diámetro. En este mismo contexto, Ichikawa et al. (1980), estudiaron la glándula parótida de ratón del desierto y describieron básicamente la morfología de los gránulos secretorios destacando su densidad electrónica y precisando a su membrana plasmática como una línea simple, para unos y de estructura trilaminar para otros gránulos.

Mas aún, Takano et al. (1993) en relación a los gránulos de zimógeno describieron que en ellos la distribución individual de proteínas difiere notablemente en las células de la glándula parótida. De este modo, demostraron que la amilasa se concentra mayoritariamente en la región más electro-densa mientras que aglutinina se ubica en la región de baja densidad de los gránulos. Así mismo, una proteína rica en prolina e histatina se distribuye en forma homogénea en toda la superficie del gránulo sin presentar concentraciones especiales en las regiones de baja o alta densidad electrónica.

Tanto grandes mitocondrias con elevada cantidad de crestas y con fracciones volumétricas importantes, como largas y marcadas cisternas de retículo endoplásmico rugoso, son observadas tanto en este estudio como los presentados por Hand (1973) y Tandler \& Erlandson (1976) todos hallazgos visualizados en observaciones de microfotografías electrónicas de transmisión realizadas en células acinares de parótida normales de ratas.

Con respecto al compartimento nuclear, nuestros re- sultados evidenciaron un núcleo de forma esférica de ubicación basal con una membrana nuclear claramente observable y continua. El nucleoplasma contiene mayoritariamente eucromatina en un $80 \%$ representando una alta tasa de expresión génica y heterocromatina adherida al envoltorio nuclear. Estas características descritas son coincidentes con las observaciones de Riva \& Riva Testa (1973) obtenidas desde células acinares de la glándula parótida humana, enfatizando que la distribución de los tipos de cromatina son naturalmente dependiente de los estadios de su propio ciclo celular.

Finalmente, creemos que los resultados de este estudio proporcionan una valiosa información relativa a la constitución morfológica ultraestructural de una célula acinar normal de parótida y que, contando con esta descripción y/ o evaluación morfométrica de sus componentes se podrá evidenciar las eventuales modificaciones a este patrón normal de constitución celular en medida que las parótidas sean activadas con estimulaciones externas como, por ejemplo, las ejercidas por el láser infrarrojo de baja intensidad con el propósito de incrementar la actividad de síntesis, traslado y secreción de proteínas.

\section{AGRADECIMIENTOS}

Este trabajo es el resultado de las investigaciones derivadas del proyecto DI 12-0024.

CORNEJO, R.; GARRIDO, O.; MATAMALA, F.; SILVA, H.; MARDONES, A.; LAGOS, K. \& HUEICHAPAN, O. Ultrastructural morphometric analysis from normal parotid cells in rat. Int. J. Morphol., 31(4):1205-1209, 2013.

SUMMARY: From 10 female rats weighing approximately $250 \mathrm{~g}$ and aged 4 months, samples of parotid gland were obtained surgically which were treated with transmission electronic microscopy in order to obtain microphotographs with final increases of up to 21,300 X. Morphometric techniques were applied to these microphotographs to quantify the volumetric fractions that the different components occupy in these normal cells, thus describing their volumes and relating them to their functionality in this normal cell. Volumetric fractions were evaluated pertaining to: cytoplasm, nucleus, mitochondria, rough endoplasmic reticulum (RER), zymogen granules, eu and heterochromatin. Likewise, cell and nuclear areas were quantified. With the numerical data from the morphometric evaluation of its components, it was possible to determine the distribution pattern of the organelles and functionality of this cell active in protein synthesis and secretion represented by diastase zymogen granules and various salivary proteins.

KEY WORDS: Morphometry; Parotid gland; Acinar cell.

\section{REFERENCIAS BIBLIOGRÁFICAS}

Amsterdam, A.; Ohad, I. \& Schramm, M. Dynamic changes in the ultrastructure of the acinar cell of the rat parotid gland during the secretory cycle. J. Cell Biol., 41(3):753-73, 1969.

Avery, J. \& Chiego, D. Principios de histología y embriología bucal con orientación Clínica. 3a ed. Madrid, Elsevier, 2007. p.195.
Ceccotti, E.; Sforza, R.; Carzoglio, J.; Forteza, J.; Luberti, R. \& Flichman, J. El diagnóstico en clínica estomatológica. Buenos Aires, Médica Panamericana, 2007. p.483.

Cope, G. H. Stereological analysis of the duct system of the rabbit parotid gland. J. Anat., 126(Pt. 3):591-604, 1978. 
CORNEJO, R.; GARRIDO, O.; MATAMALA, F.; SILVA, H.; MARDONES, A.; LAGOS, K. \& HUEICHAPAN, O. Análisis morfométrico ultraestructural de células normales de glándula parótida de rata. Int. J. Morphol., 31(4):1205-1209, 2013.

Gal Iglesias, B.; López Gallardo, M.; Martín Velasco, A. \& Prieto Montalvo, J. Bases De La Fisiología. 2a ed. Madrid, Tébar, 2007. pp.271-5.

Gómez De Ferraris, M. \& Campos, M. A. Histología, embriología e ingeniería tisular bucodental. 3a ed. México D.F., Médica Panamericana, 2009. p.191.

Hand, A. R. Morphologic and cytochemical identification of peroxisomes in the rat parotid and other exocrine glands. $J$. Histochem. Cytochem., 21(2):131-41, 1973.

Ichikawa, A.; Ichikawa, M. \& Hirokawa, N. The ultrastructure of rapid-frozen, substitution fixed parotid gland acinar cells of the mongolian gerbil (Meriones meridianus). Am. J. Anat., 157(1):107-10, 1980

Kühnel, W. Atlas color de citología e histología. 11a ed. Madrid, Médica Panamericana, 2005. p.278.

Riva, A. \& Riva-Testa, F. Fine structure of acinar cells of human parotid gland. Anat. Rec., 176(2):149-65, 1973.

Riva, A.; Testa-Riva, F.; Del Fiacco, M. \& Lantini, M. S. Fine structure and cytochemistry of the intralobular ducts of the human parotid gland. J. Anat., 122(Pt. 3):627-40, 1976.

Ross, M. \& Pawlina, W. Histología, Biología Celular. 5a ed. Buenos Aires, Médica Panamericana, 2007. p.558.

Rovira, C. A.; Ramos, G. A. \& De Juan, D. M. Actualizaciones seram radiología de cabeza y cuello. Madrid, Médica Panamericana, 2009. p.55.

Takano, K.; Malamud, D.; Bennick, A.; Oppenheim, F. \& Hand, A. R. Localization of salivary proteins in granules of human parotid and submandibular acinar cells. Crit. Rev. Oral Biol. Med., 4(3-4):399-405, 1993.

Tandler, B. \& Erlandson, R. A. Ultrastructure of baboon parotid gland. Anat. Rec., 184(1):115-31, 1976.

Weibel, E. R. Stereological principles for morphometry in electron microscopic cytology. Int. Rev. Cytol., 26:235-302, 1969.

\author{
Dirección para Correspondencia: \\ Dr. Ricardo Cornejo \\ Facultad de Medicina \\ Universidad de La Frontera \\ Casilla 54-D, \\ Temuco \\ CHILE
}

Email: ricardo.cornejo@ufrontera.cl

Recibido : 14-01-2013

Aceptado: 22-10-2013 